\title{
Second REP-LECOTOX Workshop "Trends in Ecological Risk Assessment", University of Novi Sad, Serbia, 21-23 September 2009
}

\author{
Ivana Teodorović, Sonja Kaišarević, Ivana Planojević, Svetlana Fa, Vanja Dakić, Kristina Pogrmić, Jelena Hrubik, \\ Branka Glišić, Radmila Kovačević
}

The workshop titled "Trends in Ecological Assessment" was the second workshop organized by the Laboratory for Ecotoxicology (LECOTOX, University of Novi Sad, Faculty of Sciences (UNSFS), Novi Sad, Serbia) within the frame of the EC FP6-funded project INCO-CT2006-043559-REP-LECOTOX UNSFS-Reinforcement of Research Potential of the Laboratory for Ecotoxicology. The objectives of the workshop were:

a. To present comprehensive information about the current state, challenges and trends in the field of both chemical and ecological risk assessment (ERA), with special reference to application into environmental management practice;

b. To provide local and regional professionals, decision makers and different stakeholders (e.g. industry, regulatory agencies, non-governmental organisations (NGOs)...) with the comprehensive overview of the valid European Union (EU) regulations and future trends regarding chemical and ecological risk assessment (with special reference to Regulation on Registration, Evaluation, Authorisation and Restriction of Chemicals (REACH)-EC No. 1907/2006 and Water Framework Directive (WFD));

c. To serve as a forum for networking, knowledge and information exchange and dissemination, providing a substantial contribution to Serbian/Western Balkan Countries societies in the processes of transposition of and harmonisation with the EU environmental legislation, policy and practice.

The workshop was structured in two large sessions.

\footnotetext{
* Correspondence: teodorovic@beocity.net Laboratory for Ecotoxicology (LECOTOX), Department of Biology and Ecology, University of Novi Sad, Faculty of Sciences, D. Obradovica Sq. 2,
} 21000 Novi Sad, Serbia
Session 1: Risk assessment of chemicals with special attention to REACH, which was divided according to topics into three sub-sessions:

\section{A. Legislative aspect;}

1.B. Emerging substances and nano-materials: analyses, environmental fate, effects, ERA;

1.C. Incorporating "omic" information into risk assessment and policy.

Session 2: Ecosystem risk assessment, which was also divided into three sub-sessions:
2.A. Aquatic ecosystems, ERA in WFD and Ground- water Directive;
2.B. Special ERA topic-up-scaling;
2.C. Terrestrial ecosystems.

Two keynote lecturers and even eighteen invited speakers (Figure 1) from well-known European research institutions presented extremely diverse ERA topics, ranging from case studies to conceptual frameworks and opinion statements. To enable further exchange of experiences and information about the research potential and capacities of local (Serbian) and regional research institutions and teams, seven workshop participants were invited to present the results of their current work in the form of short oral presentations, while many others presented posters.

This report brings the highlights from presentations given by invited lecturer and some of the key messages which could be derived from rather fruitful round-table discussion organized at the end of the workshop.

In the first keynote lecture, Prof. Dr. Ivan Holoubek, RECETOX, Masaryk University, Brno, Czech Republic, discussed the ways in which the data from long-term monitoring of POPs on a large spatial scale can be used 


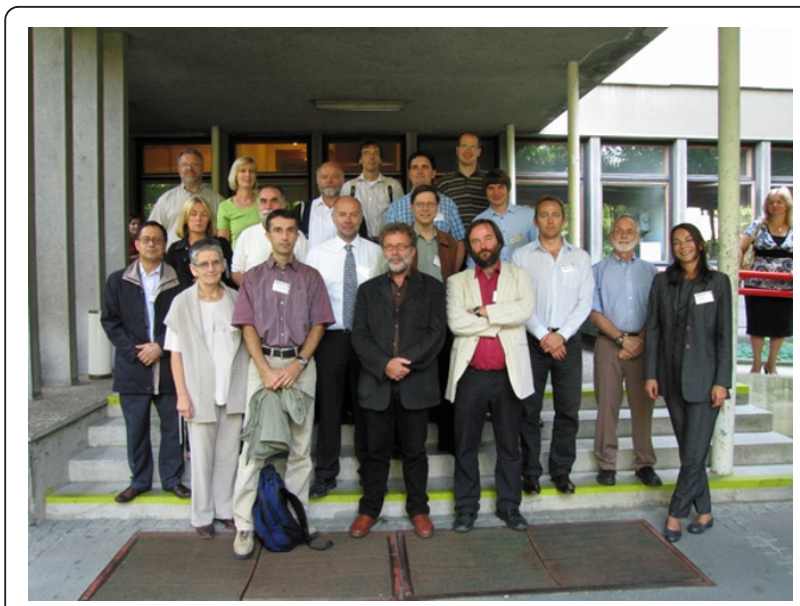

Figure 1 Invited lecturers. Second REP-LECOTOX Workshop "Trends in Ecological Risk Assessment", 21-23 September 2009, Novi Sad, Serbia. From the top row down, from left to right: Dr. Stefan Scholz (UFZ, Germany), Dr. Jakub Hofman (RECETOX, Czech Republic), Prof. Dr. Ivan Holoubek (RECETOX, Czech Republic), Prof. Dr. Ivana Ivancev Tumbas (UNSFS, Serbia), Prof. Dr. Ivan Grzetic (Belgrade University, Serbia), Dr. Ludek Blaha (RECETOX, Czech Republic), Armand Beuf (EC DG Research), Dr. Marjan Ahel (Institute Rudjer Boskovic, Croatia), Jos Brils (Deltares, The Netherlands), Prof. Dr. Jussi Kukkonen (University of Joensuu, Finland), Dr. Mikhail Beketov (UFZ, Germany), Prof. Dr. Radmila Kovacevic (REP-LECOTOX project coordinator, Serbia), Dr. Tvrtko Smital (Institute Rudjer Boskovic, Croatia), Dr. Joop Vegter (TNO, The Netherlands), Dr. Werner Brack (UFZ, Germany), Dr. Brett Lyons (CEFES, UK), Prof. Dr. Val Beasley (University of Illinois, USA) and Dr. Ivana Teodorovic (workshop organizer, LECOTOX, Serbia). Missing from the photo: Dr. Dimosthenis Sarigiannis (JRC, Ispra, Italy) and Ms Katarina Krinulovic (Ministry of Environment and Spatial Planning, Serbia).

for risk assessment. All the invited speakers within chemical risk assessment session agreed that the REACH regulation presented a regulatory driver, which would certainly stimulate further ecotoxicological research. Dr. Dimosthenis Saragianis (EU Joint Research Center, Ispra, Italy) stressed that current orientation in chemical risk assessment was to tackle single substances affecting individual health points while, in reality, humans are exposed to mixtures of chemicals. By presenting a system approach which could effectively support integrated risk assessment of chemicals in mixtures, he listed some of the top priorities for future multidisciplinary work, which included development/refinement of algorithms which would fuse environmental, biomonitoring and epidemiological data; use of biology-based models for accurate estimation of biologically effective dose and the need for functional coupling of toxicodynamics with toxicogenomics data to assess combined exposure and associated health effects.

REACH requires, inter alia, a series of mandatory toxicological and ecotoxicological tests, including multiple testing on vertebrates. Dr. Stefan Scholz (UFZ, Leipzig,
Germany) pointed out that the recent estimates showed that EU regulators by far underestimated the number of chemicals to be registered and consequently the costs and number of animal tests to be performed during registration procedure and concluded that alternative tests, which are highly supported and welcomed by $\mathrm{REACH}$ regulation, seemed to be more urgent than anticipated. By presenting a number of illustrative examples using standard test species-Danio rerio fish-as a model, he showed how system biology or "omics" could be used in integrative testing strategies. He underlined that one of the main challenges would be to link molecular and cellular interactions and effects to individuals, populations, communities and ecosystems. Answering to the challenge, Dr. Brett Lyons (CEFAS, UK) presented the application of "omics" in marine monitoring. He showed the data from impressive joint programme underpinning OSPAR JAMPS-flatfish diseases and pathology monitoring (using platforms such as cDNA microarrays) as a top-level biological end-point of historical exposure to impacted environments.

The second, outstanding keynote lecture was given by Dr. Werner Brack (UFZ, Leipzig, Germany). He underlined the fact that monitoring programmes and target analysis had, in general, necessarily focused on a limited number of chemicals (underpinned even with the current concept of WFD-stipulated $33+8$ priority substances lists). The effect prediction and risk assessment of contaminated sediments based on target analytes always run the risk to ignore important or even key chemicals causing effects. Thus, in many cases, the agreement between measured effects and expected effects based on chemical analysis is poor. To overcome this problem, the concept of effect-directed analysis (EDA) has been developed to focus chemical analysis on those compounds causing the effects. EDA combines toxicity testing with fractionation procedures to isolate toxic fractions and individual toxicants, and non-target chemical analysis and structure elucidation to identify causative toxicants. Several successful studies (including the results of an on-going project on the Sava River presented by Dr. Tvrtko Smital, Rudjer Bošković Institute, Zagreb, Croatia, later during the session) demonstrated that EDA was indeed a powerful tool to identify known and unknown toxicants. However, Dr. Brack emphasized the still existing shortcomings and limitations of EDA and some of the research needs to address them, such as (1) novel extraction and dosing techniques considering bioavailability, (2) in vitro and in vivo testing with higher diagnostic power, (3) improved fractionation procedures exploiting a broad range of physico-chemical properties for separation but reducing expenses and the risk of artefacts by automation, (4) novel analytical and computer tools for better structure elucidation, 
(5) models for prediction of chromatographic behaviour, of mass and other spectra and of effects based on the chemical structure (quantitative structure-activity relationships and structure alerts) and (6) approaches to confirm identified chemicals as cause of the effects and as a potential hazard in the environment. In line with the former, Dr. Marjan Ahel (Rudjer Bošković Institute, Zagreb, Croatia) stressed the importance of extending analytical window to more polar compounds as a prerequisite for detection of emerging classes of aquatic contaminants, which might be essential for better ecotoxicological assessment of wastewaters and ambient waters. As the WFD directs member states to monitor macroinvertebrates and develop sediment quality standards, there is clearly scope for consideration of sediment quality as an integral part of river basin management. Yet, as presented by Jos Brils (Deltares, The Netherlands), the preliminary overview of river basin management plans (RBMP) shows extreme inconsistency across Europe-neither sediment management issues became integral part of RBMP nor sediment quality assessment plays an important role in assessing ecological/chemical status. The problem of up-scaling in ERA was tackled by Dr. Mikhail Beketov (UFZ, Leipzig). By giving a number of examples, he showed how ecological knowledge and methods, spanning from organism to ecosystem and landscape levels of complexity, provided essential scientific background for risk assessment, in the first place, regarding measuring and predicting effects of toxicants at the community and ecosystem levels. Toxic effects' alterations caused by system properties at population and community levels were discussed in particular, and the species-at-risk approach based on ecological traits was presented.

It has been generally agreed that effect-based identification of key toxicants as well as analysis, modelling and assessment of bioavailability and bioaccumulation are needed, along with better evaluation of monitoring data on contamination, toxicity, ecological quality and ecosystem services on a large scale. However, sound scientific concepts, models and decision support systems have to find their way to major stakeholders, environmental managers and even policy makers as their implementation would certainly contribute to the common European goal-higher level of ecosystem and human health protection.

The programme and short abstracts of all workshop presentations can be found in the Book of Abstracts (see Additional file 1). All workshop presentations in PDF form, as well as other information about REPLECOTOX project, are available at the official LECOTOX web site at http://www.lecotox.net.

\section{Additional material}

Additional file 1: Second REP-LECOTOX Workshop "Trends in Ecological Risk Assessment" Book of Abstracts. Book of abstracts contains the programme of the second REP-LECOTOX Workshop "Trends in Ecological Risk Assessment", short abstracts of key note, invited oral and poster presentations and a list of participants with their contact details

Received: 16 December 2010 Accepted: 2 February 2011 Published: 2 February 2011

doi:10.1186/2190-4715-23-6

Cite this article as: Teodorović et al:: Second REP-LECOTOX Workshop

"Trends in Ecological Risk Assessment", University of Novi Sad, Serbia, 21-23 September 2009. Environmental Sciences Europe 2011 23:6.

\section{Submit your manuscript to a SpringerOpen ${ }^{\circ}$ journal and benefit from:}

- Convenient online submission

- Rigorous peer review

- Immediate publication on acceptance

- Open access: articles freely available online

- High visibility within the field

- Retaining the copyright to your article

Submit your next manuscript at $>$ springeropen.com 